\title{
Fetal Arrhythmia
}

\section{Ana Bianchi}

\section{ABSTRACT}

The normal cardiac frequency of the fetus is between 120 and $160 \mathrm{bpm}$. Fetal arrhythmia happens in 1 to $2 \%$ of pregnancies. Most of them are beginning with spontaneous solution. Less than $10 \%$ implies a real problem, such as fetal hydrops and fetal death. The evaluation of the cardiac rhythm is usually done by two methods: $\mathrm{M}$ mode and Doppler. Each method has its advantages and limitations. It is important for the physician to be aware of the etiology, development, and natural history of these arrhythmias, and the diagnostic and therapeutic options available. A simultaneous record of both ventricular and atrial contractions with a four-chamber view is useful for assessing the relation of atrioventricular (AV) connection in fetuses with arrhythmias. We will present different types of arrhythmias: tachycardia, bradycardia, irregular rhythm, paroxysmal supraventricular tachycardia (PSVT), atrial fibrillation (AFL). Fetal bradycardia is mainly due to AV block. Half of all cases are caused by associated congenital heart disease (CHD), or by maternal SS-A antibodies. Efficacy of prenatal treatment for fetal AV block is limited. Most fetuses with both PSVT and atrial flutter are successfully treated by transplacental administration of antiarrhythmic drugs. Digoxin is widely accepted as a first-line antiarrhythmic drug. Sotalol, flecainide, and amiodarone are used as second-line drugs.

Keywords: Arrhythmia, Atrial fibrillation, Paroxysmal supraventricular tachycardia.

How to cite this article: Bianchi A. Fetal Arrhythmia. Donald School J Ultrasound Obstet Gynecol 2018;12(1):60-62.

\section{Source of support: Nil}

\section{Conflict of interest: None}

\section{INTRODUCTION}

The normal cardiac frequency of the fetus is between 120 and $160 \mathrm{bpm}$. Fetal arrhythmia is rare and only happens in 1 to $2 \%$ of pregnancies. Most of them are beginning with spontaneous solution but $<10 \%$ implies a real problem, such as fetal hydrops and fetal death.

The majority are treatable in utero so that it is important to identify which type is to treat adequately and avoid preterm deliveries.

Echocardiography is still the best technique for the study of fetal arrhythmia. With this technique we

\section{Director}

Department of Prenatal Medicine (UMP), Centro Hospitalario Pereira Rossell, Montevideo, Uruguay

Corresponding Author: Ana Bianchi, Director, Department of Prenatal Medicine (UMP), Centro Hospitalario Pereira Rossell Montevideo, Uruguay, e-mail: anabbianchi@gmail.com can infer the electrical phenomena on the heart from the mechanical ones of the cardiac structures and flux movement. ${ }^{1,2}$

The evaluation of cardiac rhythm is usually done by two methods: M mode (Fig. 1) and Doppler. Each method has its advantages and limitations. It also depends on the complexity of the arrhythmia and the qualifications of the operator.

There are two types of Doppler techniques: pulsed Doppler and tissue Doppler. The former studies the flux movement of the blood, while the latter studies the movement of the cardiac muscle.

It is increasingly important for the physician to be aware of the etiology, development, and natural history of these arrhythmias, and also the diagnostic and therapeutic options that are available.

A correct evaluation is essential to determine if there is or not a CHD associated with rhythm disorder.

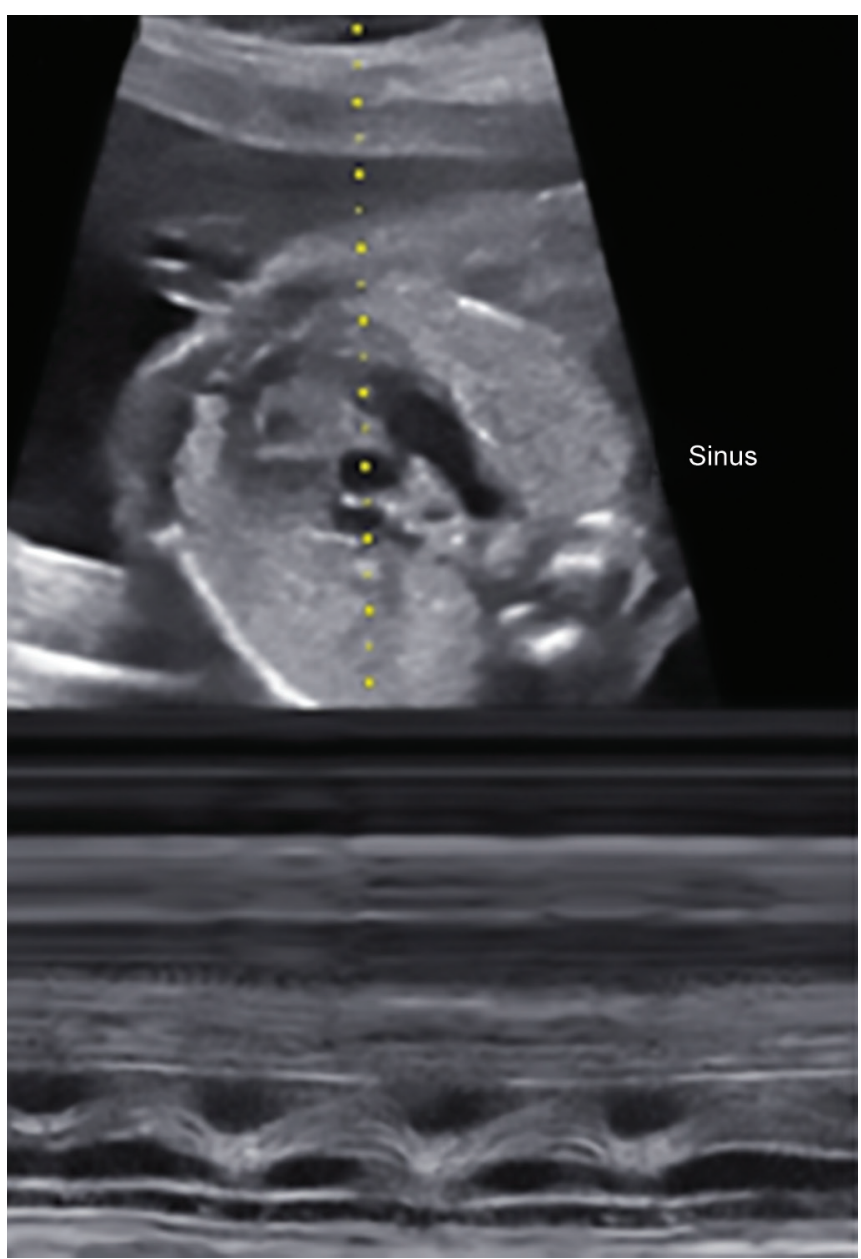

Fig. 1: M-mode 


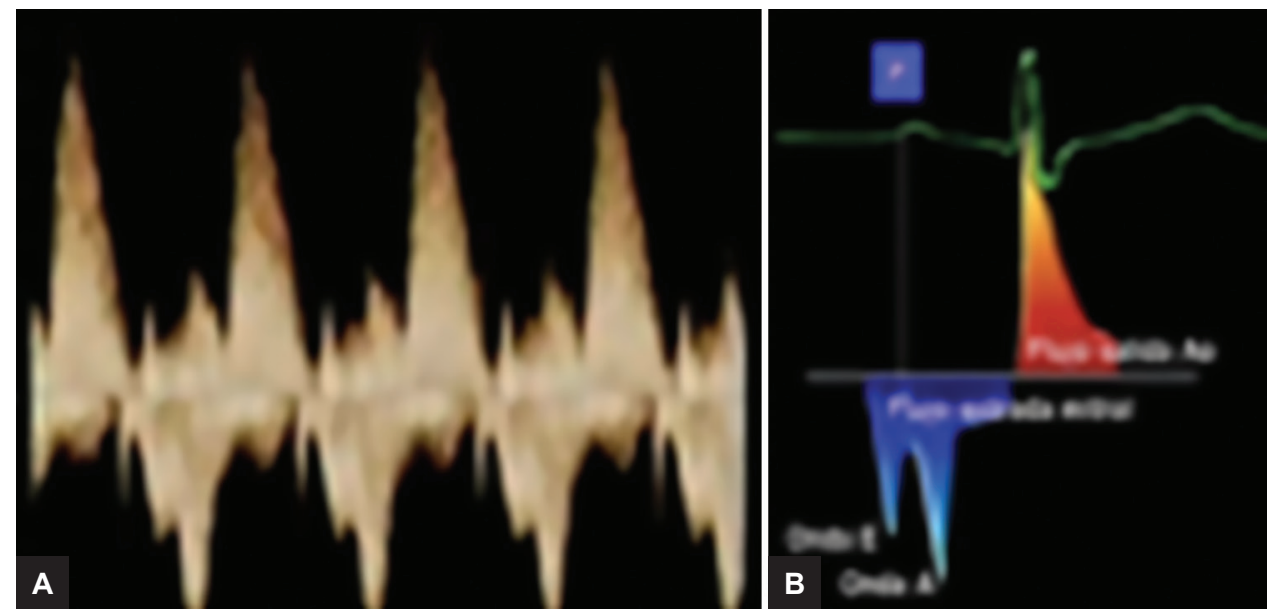

Figs $2 A$ and $B$ : Sinus rhythm

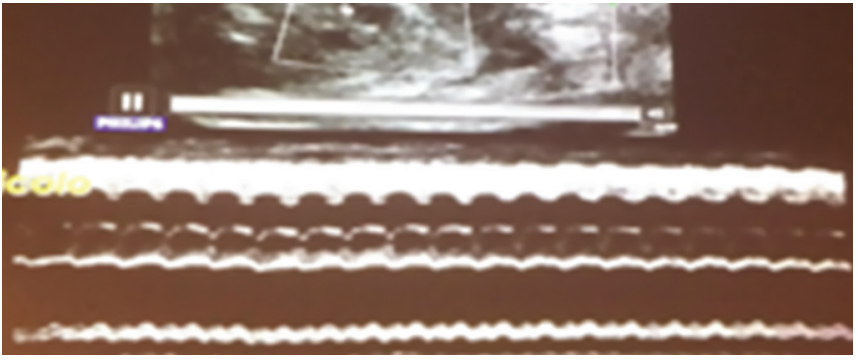

Fig. 3: Supraventricular tachycardia

There are three types of fetal arrhythmias. The most common form is irregular heartbeat, mainly caused by ectopic beats. When the ventricular rate is faster than $180 \mathrm{bpm}$ or slower than $100 \mathrm{bpm}$, such fetal arrhythmia is classified as fetal tachycardia or fetal bradycardia respectively.

An M-mode trace of ventricular and atrial motion demonstrates cardiac rhythm and rate. A simultaneous record of both ventricular and atrial contractions with a four-chamber view is especially useful for assessing the relation of $\mathrm{AV}$ mechanical connection in fetuses with arrhythmias (Fig. 2) ${ }^{3,4}$

We have different types of arrhythmias: tachycardia, bradycardia, irregular rhythm. The importance of doing the proper diagnosis offers different options of treatments and obstetric conducts. The sinusal node has parasympathetic and sympathetic innervation. The fetal myocardium is more rigid and so it has a reduced preload and afterload than the adult heart.

Fetal tachycardia is diagnosed when the fetal ventricular heart rate is faster than $180 \mathrm{bpm}$. We have three types of tachycardia: sinus tachycardia, supraventricular tachycardia, and atrial flutter.

\section{ATRIAL EXTRASYSTOLE}

They can appear isolated and sporadic, without defined patterns of bigeminism.
In atrial begeminism where there is no conduction to the ventricle, it can generate ventricular bradycardia of about 70 to $100 \mathrm{bpm}$. It can be confused with atrioventricular block; we use Mode M to make the diagnosis. Many fetuses frequently present with extrasystole, alternating begeminism forms, and trigeminism, and these fetuses run the risk of ending in supraventricular tachycardia.

The auricular extrasystoles do not cause fetal suffering, neither hypoxia with a positive evolution nor disappear during pregnancy or after birth. Anyway, they are weekly checked to see its evolution.

The ventricular extrasystoles are very rare and have a benign evolution. The most complicated fetal tachycardia is PSVT (Fig. 3) and AFL.

Fetal tachycardia is classified based on the relation between the AV contraction observed by fetal echocardiography and tachycardia with dissociated atrial contraction. Although tachycardia is sometimes intermittent during prenatal examination, the chance of hemodynamic complications in tricuspid insufficiency and development of fetal hydrops remains high.

The cardiac frequency is about $200 \mathrm{bpm}$ and can show at regular intervals of having a physiological mechanism of reentry or ectopic repetitive circular movements of electrical stimulus being generated and produce tachycardia. Fetal Doppler evidence a decrease in cardiac output that if it takes long can lead the fetus to hypoxia or death. ${ }^{5-7}$

\section{ATRIAL FLUTTER}

Atrial frequency is 300 to $500 \mathrm{bpm}$ with a ventricle of 200 to $300 \mathrm{bpm}$. Due to AV blocking chaotic atrial movement is difficult to control in supraventricular tachycardia (Fig. 4).

Fetal bradycardia is diagnosed when the fetal ventricular heart rate is slower than $100 \mathrm{bpm}$, mainly due to AV block. Approximately half of all cases are caused 


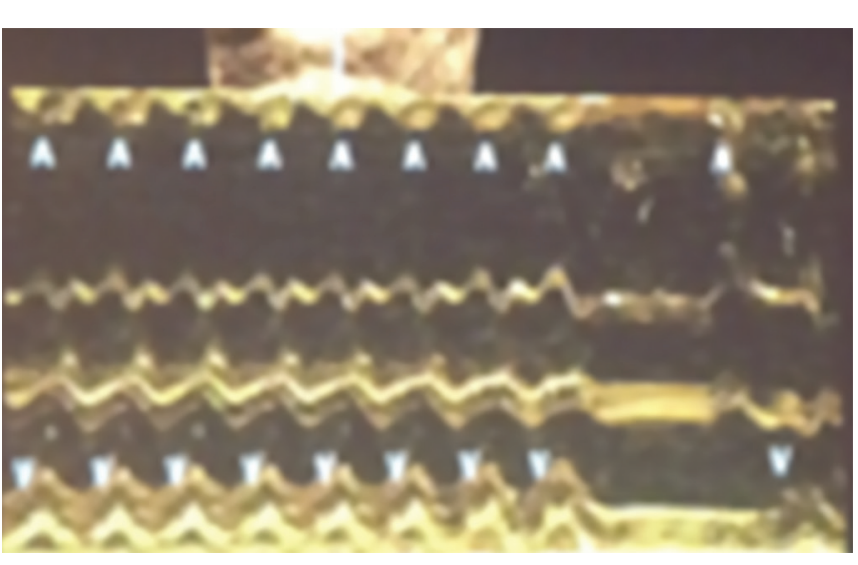

Fig. 4: Atrial flutter

by associated $\mathrm{CHD}$, and the remaining cases that have normal cardiac structure are often caused by maternal SS-A antibodies. The two most common CHD associated with AV block are left atrial isomerism and discordant AV connection.

Doppler echocardiography is useful for diagnosing fetal bradycardia. The relation and interval of atrial and ventricular contractions revealed by superior vena cava and ascending aorta Doppler flow can demonstrate the severity of AV block.

Efficacy of prenatal treatment for fetal AV block is limited compared with treatment for fetal tachycardia. ${ }^{8}$ Most fetuses with both PSVT and AFL are successfully treated by transplacental administration of antiarrhythmic drugs. ${ }^{9-11}$ Digoxin is widely accepted as a first-line antiarrhythmic drug. Obstetrics follow-up before starting the treatment includes electrocardiogram hepatic and renal function evaluation. Sotalol, flecainide, and amiodarone are used as second-line drugs when digoxin fails to achieve conversion to sinus rhythm. ${ }^{12}$

\section{OBSTETRICS FOLLOW-UP}

\section{Weekly and Biweekly Control}

Pregnancy interruption depends on gestational age. Treatment with digoxin for supraventricular arrhythmias includes checking the maternal digoxinemia every 12 hours and doses no more than $2.5 \mu \mathrm{g} \mathrm{mL}$. A second option is sotalol and the third option is flecainide.

Amiadarone has a poor transplacental passage and risk of fetal and neonatal hypothyroidism. Derivation to specialized center, evaluation with cardiologist, multidisciplinary coordination for severe cases, and strong arrhythmias are highly recommended. ${ }^{13-15}$

\section{REFERENCES}

1. Yagel S, Cohen SM, Achiron R. Examination of the fetal heart by five short-axis views: a proposed screening method for comprehensive cardiac evaluation. Ultrasound Obstet Gynecol 2001 May;17(5):367-369.

2. International Society of Ultrasound in Obstetrics and Gynecology; Carvalho JS, Allan LD, Chaoui R, Copel JA, DeVore GR, Hecher K, Lee W, Munoz H, Paladini D, et al. ISUOG Practice Guidelines (updated): sonographic screening examination of the fetal heart. Ultrasound Obstet Gynecol 2013 Mar;41(3):348-359.

3. Gratacós E, Gómez R, Nicolaides K, Romero R, Cabero L. Arrhythmia fetal. En: Medicina fetal. España: Ed. Panamericana; 2009. pp. 365-384.

4. Tikanoja T, Kirkinen P, Nikolajev K, Eresmaa L, Haring P. Familial atrial fibrillation with fetal onset. Heart 1998 Feb;79(2):195-197.

5. Malvino E, Bruno MC, Gallo JP, Medrano JC, Ferrante D. Taquiaritmias supraventriculares fetales refractarias al tratamiento inicial. Medicina (B Aires) 2005 Mar-Apr;65(2):138-142.

6. Fouron JC. Fetal arrhythmias: the Saint Justine hospital experience. Prenat Diagn 2004 Dec;24(13):1068-1080.

7. Feit LR. Fetal cardiac arrhythmias: diagnosis and managements. Med Health R I 2001 May;84(5):161-164.

8. Krapp M, Bashat AA, Grembruch U, Gripel A, Genner U. Flecainide in the intrauterine treatment of fetal supraventricular tachycardia. Ultrasound Obstet Gynecol 2002 Feb;19(2):158-164.

9. Simpson JM, Sharland GK. Fetal tachycardia: management and outcome of 127 consecutive cases. Heart 1998 Jun;79(6):576-581.

10. Gembruch U, Yagel S, Silverman N. Fetal tachyarrhythmia. In: Yagel S, Silverman N, Gembruch U, editors. Fetal cardiology. London: Dunitz; 2003. pp. 355-361.

11. Cuneo BF, Strasburguer JF. Management strategy for fetal tachycardia. Obstet Gynecol 2000 Oct;96(4):575-581.

12. Husain A, Hubail Z, Al Banna R. Fetal supraventricular tachycardia, treating the baby by targeting the mother. BMJ Case Rep 2013 Apr;2013:008515.

13. Abel DE. Fetal dysrhythmias: a primer for the obstetrician/ gynecologist. Obstet Gynecol Surv 2013 Jul;68(7):521-525.

14. Meijboom EJ, van Engelen AD, van de Beek EW, Weijtens $O$, Lautenschutz JM, Benatar AA. Fetal arrhythmias. Curr Opin Cardiol 1994 Jan;9(1):97-102.

15. van Engelen AD, Weijtens O, Brenner JI, Kleinman CS, Copel JA, Stoutenbeek P, Meijboom EJ. Management outcome and follow-up of fetal tachycardia. J Am Coll Cardiol 1994 Nov;24(5):1371-1375. 